\title{
Comparative Analysis of Selected Common Stocks Listed In Global and Indian Stock Exchanges
}

\author{
Ridhvika K Shetty, Assistant Professor, MSNM Besant Institute of PG Studies Bondel. \\ Email Id: ridhvikashetty@gmail.com Mobile No: 7899413256
}

\begin{abstract}
Key words: BSE,

Tokyo stock exchange, London Stock Exchange, Fluctuations, Average returns, risk, alpha \& Beta
\end{abstract}

Stock Market has a major influence in the Indian Economy, playing a crucial role in the evolution of the Economy. The Indian Stock market is majorly influenced by the Internal as well has external factors which play a significant role in the fluctuations of the share market in India. The intention behind this paper is doing a comparative study of common stocks like Maruti Suzuki which is listed in BSE as well as in Tokyo stock exchange and HUL which is listed in BSE along with London Stock exchange, their return and risk analysis using tools like Average return, alpha \& beta. Similarly we even analyse how a particular common stock listed in international market impacts similar stock listed in domestic market and vice versa which would be useful for prediction of future fluctuations of the share price in a better way which will help the investors.

\section{INTRODUCTION:}

The share market is a source for companies to raise funds and for investors to buy part-ownership in growing businesses and grow their wealth. The stock market can be an intimating place where it is glorious to watch how investor's make money in a day at the same time $\&$ at the same time lose money in day. But ever since the change in time and technology research and risk taking ability is now possible for a common man to invest in markets. The study is related to the factors responsible for the Indian market to influence International Market and vice versa due to the internal or external news related to that company and how it impacts the share prices of that particular company. The research is done on two stocks, Maruti which is listed BSE as well as
Tokyo stock exchange and secondly Hindustan Unilever which is listed in BSE and London stock exchange. These companies are either the subsidiaries of their foreign counterpart or a merged company or companies that have similar operations.

These stock markets have major impacts in the Indian stock market that influence their fluctuation to a great extent. The research is based on 5 years of data collection and analysis using tools like average returns, Alpha \& Beta of stock \& Index, in the above analysis a comparative analysis of its risk and return for stock Maruti Suzuki listed in BSE Index has been taken into consideration, similarly Suzuki stock which is listed in Tokyo exchange has been also considered 
and the impact on the performance based on return and risk is been analysed. Another stock analysis is done with stock HUL which is listed in BSE and London stock exchange similar analysis is done as how any positive or negative news impact which is on the stock listed in international exchanges has a tremendous impact and post impact effect on the stock which includes heavy buying or selling on domestic exchange and vice versa.

\section{LITERATURE REVIEW:}

\section{(Samadder, 2018)}

This paper studied the integration of Indian stock market with that of the other developed stock market. Through the investor will come to know the diversification of portfolio and risk associated with it. With the help of correlation and other statistic tool he found that there exist a strong diversification of the foreign Portfolio is also influenced by the Global Economy.

\section{(Mukharjee, 2007)}

In his research he found that the Indian stock market was open and became global from the year 2002 onwards. The proof that he gave us was the Asian crisis that impacted the market in the Mid late nineties had affected us but not much the reason being we had an closed government then, however has the time passed by the Indian stock market such BSE and NSE was influenced by the stock market of the world, at an minor level.

\section{(Mandaviya, 2014)}

This paper studies the FII and FDI to India and the reaction of Indian Market to the global cues. Various stock exchanges that are influenced by the socio economic factors, the Stock exchanges are US stock exchange, Hong Kong stock exchange, Australia, Germany and Shanghai Stock Exchange. With the study they proved that Indian stock exchange influence the international stock exchange and vice versa this was done with the help of Qualitative and Quantitative techniques.

\section{(Chaitanya, 2015)}

The past 20 years global market has experienced some astonishing changes. Globalisation and Liberalisation procedures were recognized by various countries including India, thus opening the barriers for International trade. Under this study looking for global Forex and their impact in the worldwide markets including India. The research paper concentrates on pattern development of Asian Stock market lists, thus comprising the association with other markets as well.

\section{(Mukhopadyay, 2007)}

This research finding is basically related to the Dynamic relationship between the NSE and NASDAQ. This paper studies the correlation and granger causality and applying to GARCH model to examine whether the movement and the instability between the USA and India are related. The study found that when the model was applied it affects the conditional return of the NIFTY. The paper concluded that NASDAQ in determining the NIFTY's overnight changes 


\section{(Srivastav, 2017)}

The main objective of the study is to analyse Correlation between Bombay stock exchange indices with other selected International stock markets indices. Secondary data is used in this study from 01/012011 to $01 / 02 / 2016$. Monthly closing prices of selected indices have been collected from the studied stock exchanges. Correlation, rate of change, moving average MACD (Moving average convergence and divergence) are the tools used to know the connection and link of BSE with other selected stock exchanges.

\section{(Hashmi, 2017)}

This paper uses the regression and Granger casual test to identify the effect of the financial crisis on the Major stock exchanges in the world. The major objective of the study is to find out the interdependence between the stock exchanges in other country. The final data so obtained suggests that the financial crisis so taken place help to rein form the stability of the market and also develop a strong interdependence between the stock exchanges of the world.

\section{OBJECTIVE OF THE STUDY:}

1. To examine the relationship between the stocks listed on Indian stock markets with global markets using risks and returns analysis.

2. To do a comparative study of how the impact of one common stock listed on Indian exchange impacts similar stock in international market \& vice versa.

\section{NEED FOR THE STUDY:}

Every individual that enters into the stock market with an intention to earn money for their investments, it is only possible when the investor is able to read and understand the market in a better way and only when all that elements which influence the movement of that share is understood by the investor, one of the elements is the influence of the international market. Majority of company listed in the stock exchange are elated to their international counterpart, so any information relating to that company also influences the share market here. This paper deals with such information related to particular stock and other domestic reason for the fluctuation of the stocks in India and in the International Market, and can identify what is the relationship between various markets and how with these data an investor can predict the future scope of that particular stock \& can get an idea what is the risk that is associated with every return and vice versa.

\section{RESEARCH METHODOLOGY:}

The research is done taking into consideration two companies belonging to two different sectors, these companies are listed in Indian Stock Exchange as well as International stock exchange and belong to the same industries in India as well as in International Stock exchange. The first company is Maruti Suzuki which is listed in Bombay stock exchange and Suzuki Motor corp which is listed in Tokyo stock exchange; both these companies belong to the automobile industry in their respective countries. Second company is Hindustan Unilever which is one of 
the biggest FMCG with its presence in India and International level. Thus HUL is listed in Bombay stock exchange as well as in London stock exchange. For gathering data, secondary source of data have been used in which all the closing prices of the stocks listed in domestic and international exchanges along with closing prices of Indian \& Foreign Exchanges are gathered for research. With help of statistical tool i.e. average return, beta and alpha which have been used for data analysis.

\section{DATAANALYSIS AND INTERPRETATION:}

Table (1) showing Average Return, Alpha \& Beta of Maruti Suzuki in BSE

\begin{tabular}{|c|c|c|c|c|}
\hline Year & $\begin{array}{c}\text { Average Return } \\
\text { X (BSE) }\end{array}$ & $\begin{array}{c}\text { Average Return Y } \\
\text { (Maruti Suzuki) }\end{array}$ & Alpha & Beta \\
\hline $\mathbf{2 0 1 4}$ & 2.26 & 5.8 & 1.94 & 1.71 \\
\hline $\mathbf{2 0 1 5}$ & -0.37 & 2.88 & 3.07 & 0.51 \\
\hline $\mathbf{2 0 1 6}$ & 0.26 & 1.77 & 1.28 & 1.85 \\
\hline $\mathbf{2 0 1 7}$ & 2.11 & 5.25 & 4.07 & 0.56 \\
\hline $\mathbf{2 0 1 8}$ & 0.04 & 0.17 & 0.12 & 1.01 \\
\hline
\end{tabular}

Graph (1) showing Average Return, Alpha \& Beta of Maruti Suzuki in BSE
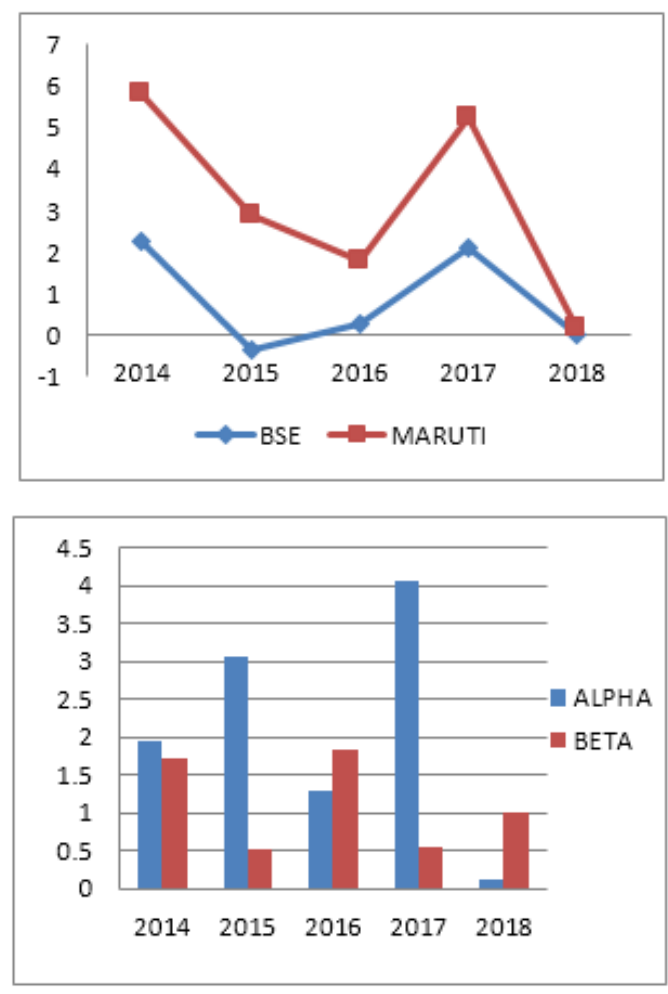

\section{Interpretation:}

In the above graph $\mathrm{X}$ is the return on market and $\mathrm{Y}$ is the return on stock, Beta measures the Volatility in the individual stock similarly the alpha measures the return of that particular share with respect to the market. In the year 2014 India election which was a major influencer to the share market played a key role in the decline of both the market and stock from returns of 2.26 to -0.37 and 5.8 to 2.88 , and alpha increased from 1.94 to 3.07 whereas beta decreased from 1.71 to 0.51 . In the year 2015-16 the individual stock return had fallen to a huge extent in spite the market had gained back the momentum from -0.37 to 0.26 , this was mainly because it was hit by the wave of budget which did not favour this segment thus reducing return from 3.07 to 1.28 and increasing risk from 0.51 to 1.85 in Maruti and BSE respectively. In the year 2016-2017 the major announcement of the partnership between Toyota and Maruti Suzuki to supply cars in India played a Major role in India to increase the demand thus leading to the increase of the average return from 1.77 to 5.25 and alpha was also increased from 1.28 to 4.07 whereas in comparison with market the risk decreased from 1.85 to 0.56 , the reduction in royalty paid towards to its parent company has been reduced has a result there is an increase in the share price of Maruti Suzuki between 2016-2017 and the market ended with an return of 2.11. In the year 2017-18 the average returns have fallen from 5.25 to 0.17 and alpha decreased from 4.07 to 0.12 whereas beta increased from 0.56 to 1.01 as the overall Indian passenger vehicle market fell into negative category with sales falling $3.6 \%$ year-on-year hence the Index returns is 0.04 . 
Table (2) showing Average Returns, Alpha \&

Beta of Suzuki Motor Corp in Tokyo Stock Exchange

\begin{tabular}{|c|c|c|c|c|}
\hline Year & $\begin{array}{c}\text { Average Return } \\
\text { X(Tokyo) }\end{array}$ & $\begin{array}{c}\text { Average Return } \boldsymbol{Y} \\
\text { (Suzuki) }\end{array}$ & Alpha & Beta \\
\hline $\mathbf{2 0 1 4}$ & 0.71 & 2.27 & 1.45 & 1.17 \\
\hline $\mathbf{2 0 1 5}$ & 0.93 & 0.36 & -0.52 & 0.95 \\
\hline $\mathbf{2 0 1 6}$ & 0.0024 & 1.4 & 1.4 & 1.22 \\
\hline $\mathbf{2 0 1 7}$ & 1.52 & 4.01 & 3.47 & 0.36 \\
\hline $\mathbf{2 0 1 8}$ & 0.05 & 0.1 & 0.06 & 0.77 \\
\hline
\end{tabular}

Graph (2) showing Average Return, Alpha \&

Beta of Suzuki in Tokyo Stock Exchange
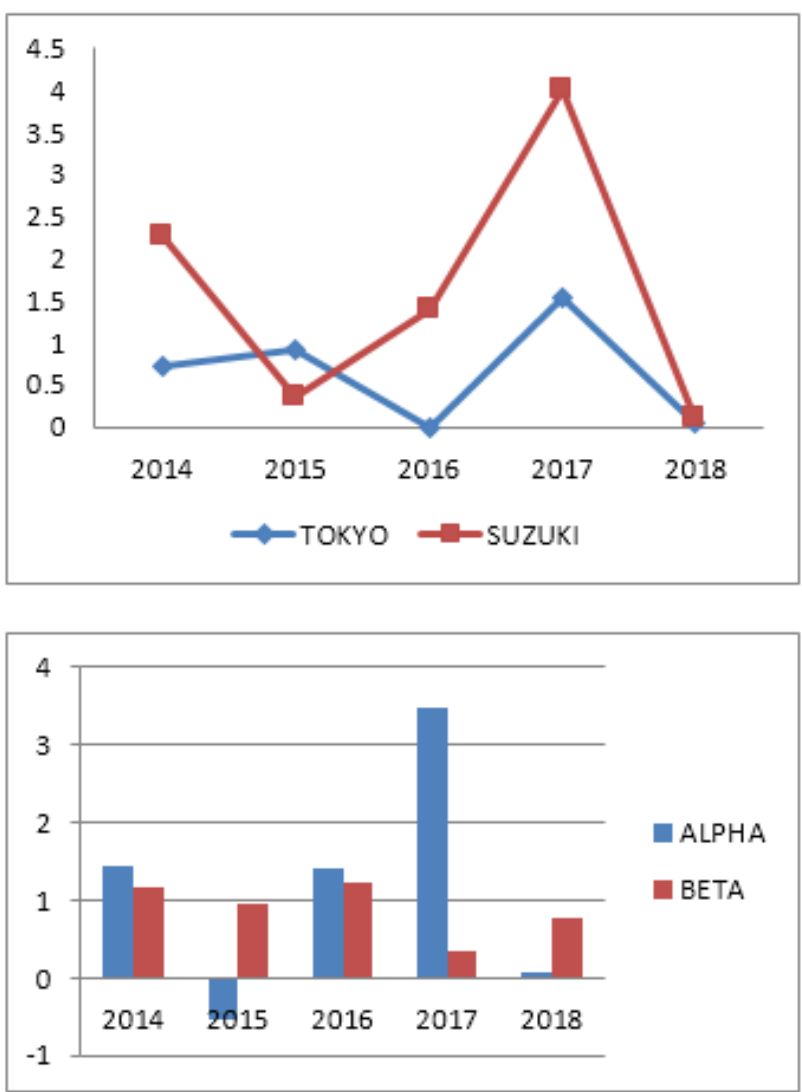

\section{Interpretation:}

In the above graph $\mathrm{X}$ is the return on market and $\mathrm{Y}$ is the return on stock, Beta measures the Volatility in the individual stock similarly the alpha measures the return of that particular share with respect to the market. In the year 2014-15 there has been a considerable fall of average returns from 2.27 to 0.36 and returns as compared with index has fallen from 1.45 to -0.52 as well as towards the end the market recovered so the risk came from
1.17 to 0.95 this was due to the budget presented in India was not much favouring this segments especially the excise duty cut being removed played a major role in the fall of share price this year has Maruti Suzuki has a major income from exports, the Tokyo market still fell to 0.36 in the year 2014-15. In year 2015-16 there was considerable increase in the share price due to which average returns increased from 0.36 to 1.4 and in comparison with the index returns was increased from -0.52 to 1.4 has there was a major launch of cars overseas especially in India thus playing a pivotal role in the increase in the share price but the index didn't gain much momentum has it still fell 0.93 to 0.0024 and the risk increased from 0.95 to 1.22 . With announcement of the financial result there was a positive impact on the share price of the company. In the year 2016-2017 there was tremendous increase in the average returns from 1.4 to 4.01 and stock returns in comparison with index returns has increased from 1.4 to 3.47 due to the partnership between Toyota and Suzuki there was a surge in the share price of the company thus increasing the share price to whereas the market also gained back the momentum and increased resulting in the price to be from 0.0024 to 1.52 by 2017 . For the year 2017 18 U.S. trade tensions and upcoming trade talks between Washington and Tokyo kept investors on edge, Threats from the Trump administration to raise the planned tariffs on $\$ 200$ billion of imports from China to $25 \%$ from the $10 \%$ proposed earlier have dampened the market mood due to which the Tokyo exchange returns fell from 1.52 to 0.05 , simultaneously Suzuki couldn't sustain the market 
with this impact on the falling returns along with the fall in sales in the Indian exchange lead to fall in the returns from 4.01 to 0.01 similarly alpha also decreased from 3.47 to 0.06 and beta increased from 0.36 to 0.77 .

Table (3) showing Average Return, Alpha \& Beta of HUL in BSE

\begin{tabular}{|c|c|c|c|c|}
\hline Year & $\begin{array}{c}\text { Average Return } \\
\text { X (BSE) }\end{array}$ & $\begin{array}{c}\text { Average Return } \boldsymbol{Y} \\
\text { (HUL) }\end{array}$ & Alpha & Beta \\
\hline $\mathbf{2 0 1 4}$ & 2.26 & 2.55 & 2.55 & 0.81 \\
\hline $\mathbf{2 0 1 5}$ & -0.37 & 1.3 & 1.33 & 1.64 \\
\hline $\mathbf{2 0 1 6}$ & 0.26 & -0.3 & -0.3 & 0.32 \\
\hline $\mathbf{2 0 1 7}$ & 2.11 & 4.37 & 4.37 & 0.72 \\
\hline $\mathbf{2 0 1 8}$ & 0.04 & 0.16 & 0.13 & 0.78 \\
\hline
\end{tabular}

Graph (3) showing Average Return, Alpha \& Beta of HUL in BSE
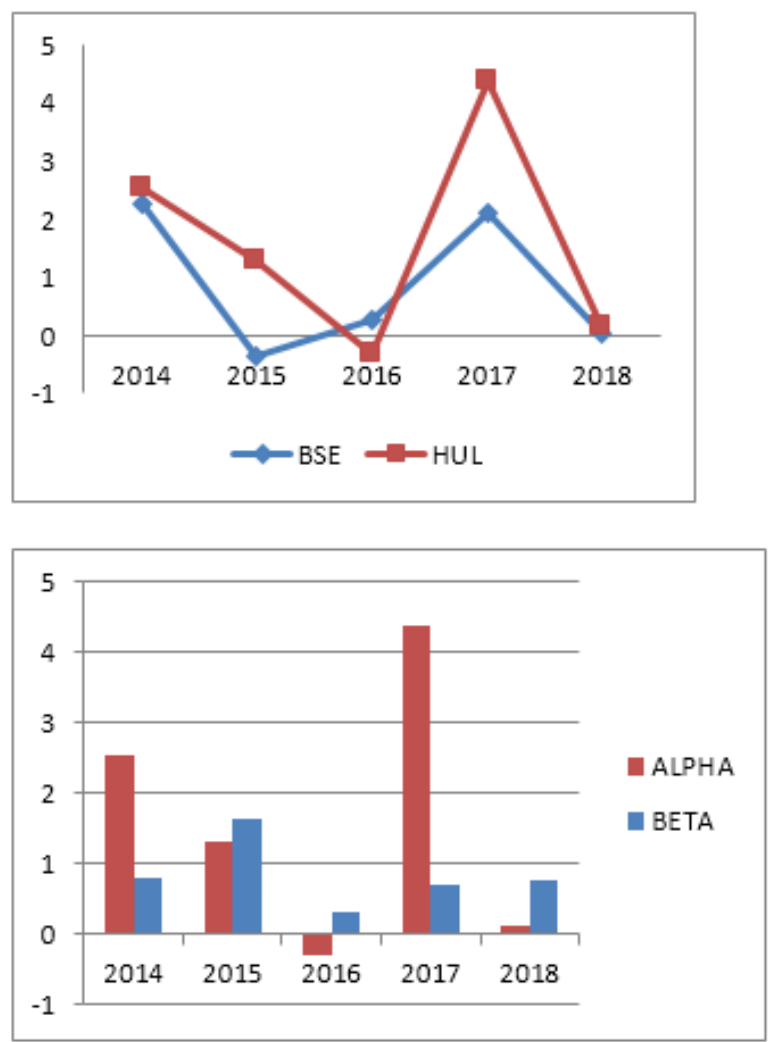

\section{Interpretation:}

In the above graph $\mathrm{X}$ is the return on market and $\mathrm{Y}$ is the return on stock, Beta measures the Volatility in the individual stock similarly the alpha measures the return of that particular share with respect to the market. In the year 2014-15 the HUL saw a fall in its average return from 2.55 to 1.3 as well as alpha decreased from 2.55 to 1.33 as there was a cut in the employment and products due to global economy coming down despite the company announcing an increase in the profit, there was a fall in the index from 2.26 to -0.37 and risk increased from 0.81 to 1.64 . And in the year 2015-16 there was not much improvement in the average return of that particular company it fell from 1.3 to -0.3 and alpha decreased from 1.33 to 0.3 due to the government selling its shares owned through SUUTI and government initiative to purchase shares in companies. However the index saw an increase to 0.26 and risk was decreased from 1.64 to 0.32 . But the year 2016-2017 saw an astonishing increase in the average return and alpha from -0.3 to 4.37 giving a slight rise in beta from 0.32 to 0.72 and increasing index return from 0.26 to 2.11 due to the announcement of the Unilever in taking over the Blue air and also Unilever to invest a huge sum in its Assam Plant and the innovation to reduce the use of Sachet. In the year 2017-2018 the average returns was tremendously down from 4.37 to 0.16 and alpha was down from 4.37 to 0.13 as the results was not favourable to the market and heavy selling happened due to which beta increased from 0.72 to 0.78 . 
Table (4) showing Average Returns, Alpha \&

Beta of HUL in London Stock Exchange

\begin{tabular}{|c|c|c|c|c|}
\hline Year & $\begin{array}{c}\text { Average Return } \\
\boldsymbol{X}(\boldsymbol{L S E})\end{array}$ & $\begin{array}{c}\text { Average Return } \\
\boldsymbol{Y}(\boldsymbol{H U L})\end{array}$ & Alpha & Beta \\
\hline $\mathbf{2 0 1 4}$ & -0.2 & 0.56 & 0.76 & 1.06 \\
\hline $\mathbf{2 0 1 5}$ & -0.35 & 1.06 & 1.46 & 1.14 \\
\hline $\mathbf{2 0 1 6}$ & 1.15 & 1.12 & 0.04 & 0.93 \\
\hline $\mathbf{2 0 1 7}$ & 0.64 & 2.08 & 1.19 & 1.38 \\
\hline $\mathbf{2 0 1 8}$ & 0.11 & 0.02 & -0.01 & 0.27 \\
\hline
\end{tabular}

Graph (4) showing Average Return, Alpha \& Beta of HUL in LSE
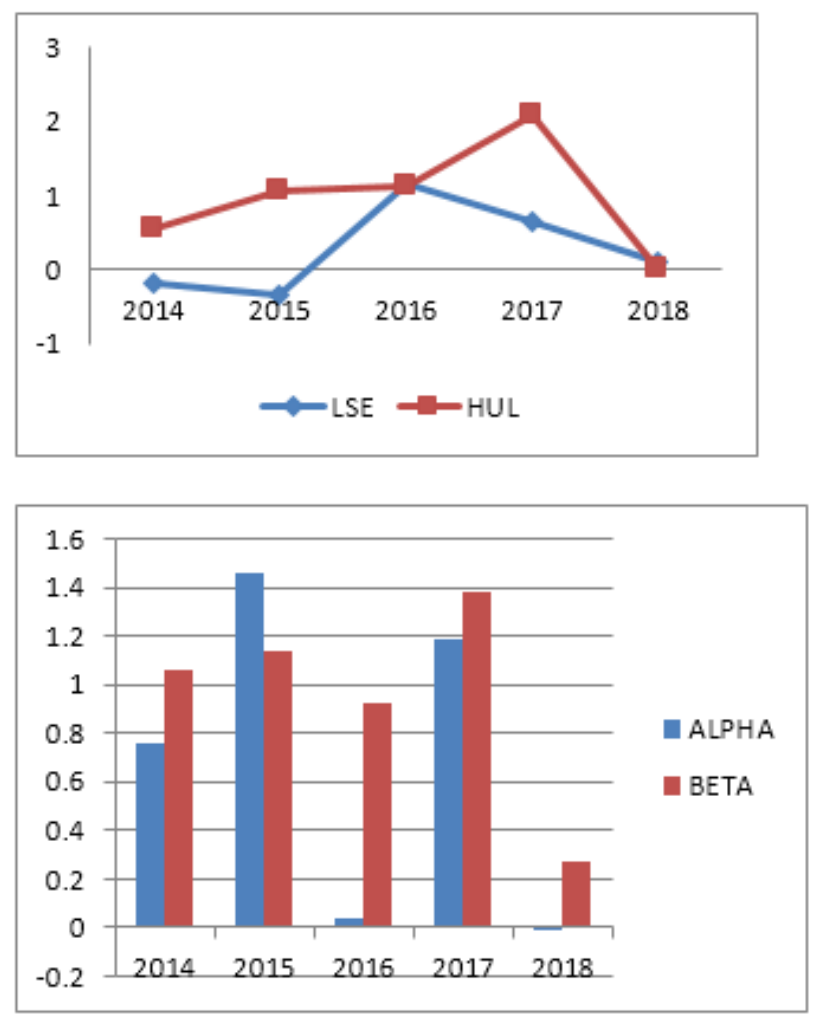

\section{Interpretation:}

In the above graph $\mathrm{X}$ is the return on market and $\mathrm{Y}$ is the return on stock, Beta measures the Volatility in the individual stock similarly the alpha measures the return of that particular share with respect to the market. In the year 2014-15 the company saw increase in the average return i.e. from 0.56 to $1.06 \&$ increase in alpha from 0.76 to 1.46 dues to the partnership with Internet.Org to have access to the children in India, in spite of fall in the index value to -0.35 and increase in beta to 1.14 .
Between the years 2015 -16 the market saw an increase from -0.35 to 1.15 , furthermore the average return \& beta on the stock was yet again stable, but alpha fell from 1.46 to 0.04 due to change in management due to resignation of Punit Misra, Executive Director and VP sales and consumer, in the year 2016-17 even though the market saw a fall to 0.64 , the stock average return saw a massive surge from 1.12 to $2.08 \&$ alpha also increased from 0.04 to 1.19 in both India as well as London due to technologically development to reduce the usage of sachets, and also the investment made to the Assam plant in India has India contributes $9 \%$ for their whole return globally Index return was stable as well as risk was slightly high from 0.93 to 1.38 . In the year 20172018 the average returns fell tremendously in Indian and London exchanges due to the results which was unfavourable for the market and India's macroeconomic condition is worsening due to rising crude oil prices, which pose risks of accelerating inflation and a wider fiscal deficit. Retail inflation is at a five-month high in June at $5 \%$ against $4.87 \%$ in the preceding month due to which alpha decreased from 1.19 to -0.01 and average returns declined from 2.08 to 0.02 but in comparison with index the beta fell from 1.38 to 0.27 .

\section{KEY FINDINGS}

In the Maruti Suzuki and Suzuki Motor corp it is found that both this big automobile companies are influenced by the domestic as well as Global news, such has when the budget was brought to notice, In which no news favoured the automobile sector and 
also the cutting of the additional excise duty on the goods exported impacted the car making company very much thus there was a decline in the share price 2.88 to 1.7 , this didn't hurt the Japanese counterpart has there was an increase in the share price due launch of their cars off shore.

Unilever being one of the largest FMCG in the world, having its subsidiaries set up all over the world and in all most all the country. This is influenced by the global news. In which India contributes around $9 \%$ of their turn over. Thus from the Investors perspective it can be a good investment. From the investor's perspective if they want invest in the company then the highest return that they can expect from HUL is 5.09 and in Unilever its parent company is 2.6. however if the investor doesn't take into consideration the risk and other factors ignores the effect of the internal and external factors then the highest possible loss that the investor can have is 3.65 and in Unilever is -1.44 for his investments.

\section{SUGGESTION:}

-Stock market is like an arena where people with experience will have a better chance of succeeding then the new comers into the markets. Thus, for the beginners in the stock market they should have basic knowledge if the market. The new investor should know when to buy the share and when to sell it. The basic guidelines for any new investor is top go to long term investment and never go for short term investment.
- The trick to trading in Equity market is that investor should select the stock that has high growth potential in the future, this is possible only after doing extensive research about that company or also those companies that are traded aggressively. And if the company has very good future prospectus then he should wait for the share price to come down depending on the support and resistance pattern. And if the share is the lowest then the investor can go for that share.

- The investor should never select companies on the basis of their return. Because a return of the company is always fluctuating and never stable. The investor should always look into the aspect of risk and return involved in that particular based on the historic data these risk and return should be calculated.

-The basic guidelines before investing are that the investor should know the details about the company that he is going to invest in. Which industry does that company belong to and how is the company performing in that particular industry and after making the investment the investor should read any press release related to that particular company

-For the investors looking for a more secure and long term investment, Maruti Suzuki, Suzuki being the major player in the automobile sector in India with almost 55\% shares, and it is difficult for any automobile sector to overthrow this particular stock in India as well as in Japan.

\section{LIMITATION OF THE STUDY}

- Only 2 companies have been taken that are listed in both exchanges this can be hindrance, has 
many other companies are listed and the data so collected is only for 5 years this can be difficult to calculate.

-Even if this research is for the purpose of the investors to help them in investing it is upon the investors whether they want to invest in that particular share or not, basically it depends on the risk taking capacity of the individual

\section{CONCLUSION}

Through this study we analysed the Indian stock market is very sensitive to any activities happening locally and globally there are lot of factors which can be unfavourable for the markets such has the inflation rate, interest rate fluctuations, company results, press release, and government policies, budget. Due to the globalisation, even forex announcements like change in crude oil prices, changes in FDI policies, Foreign exchanges like NASDAQ, DOW Jones index, foreign investments, mergers, accquitions also plays an important role in the fluctuation of the share market. The NSE \& BSE having links with other country stock exchanges plays a pivotal role in the development of the capital market of the country. Even when a company is having a subsidiary in different part of the county any changes happening in Indian market will have an impact in the stock which is listed in another exchange, so the investor should be very cautious while buying or selling the shares and should go for long term investment $\&$ be an investor not a speculator. When compared to other stock exchanges there is still room for improvement to be done in the stock exchanges of

\section{REFERENCE}

1. N. Gupta V Agarwal (2011). Comparative Study of Distribution of Indian Stock Market with Asian Markets. International journal of enterprise computing and business systems. $P g(8-15)$

2. Anukarasi. (2011). Comparative Analysis of Indian Market with Asian Stock Market

3. Judeep Biswas. (2006). Indian Stock Market In Comparison. Economic and Political Weekly. Vol. 41 No 18. Pg (1747-1752)

4. Silvio John Camilleri (2006). An Analysis of stock index distribution of selected emerging markets. MPRA Paper 62490. Pg No (03 - 16)

5. Dr C.H Chaitanya. Impact of Devaluation of Yuan on Indian Economy and Select Global Stock Indices. (2015). IJMBS Vol. 06 Issue 01. Pg No (14 - 16)

6. Sarat Dhal. (2009). Indian Stock market integrated with global and regional market. Journal of Economic Integration 24(4). Pg No (779-800)

7.Ghosh, R. (2004). Stock market Volatility an International Comparison.

8. Yonghong Jiang. The Financial Crisis and CoMovement of Global Stock Markets. MDPI Journal $\operatorname{Pg} N o(02-18)$.

9. Robert E Kennedy, J. L. Sharma (2009). A comparative Analysis of Stock Price Behaviour on the Bombay, London and New York Stock echange. Journal of Financial and Quantitative Analysis Vol 12 no 03. Pg no (391-413)

10.Mandaviya, J. s. (2014). Indian Stock Market Influenced by Global Market .

11.Mishra, A. K. (2004). Stock Market and Foriegn Exchange market in India. South Asian Journal of Management, 11.Pg No (25 - 35)

12.Mishra, K. M. (2005). A study on of Indian and World Equity Markets.

13. Debijan Mukherjee, (2007). Comparative analysis of Indian Stock Market with international Stock Market. Great Lakes Herald April 2007 Vol 01.

14.Mukhopadyay, K. K. (2007). Volatility Spillovers from the US to Indian Stock Market: a Comparison of GARCH Models.

15.Poshakwale, S. (2002). The random walk hypothesis in the emerging Indian stock market . 